\title{
Internalisation of externalities in the Spanish power generation sector. Impact of the National Plan of Allocation of Emissions in the cost of generation
}

\author{
F. Delgado, A. Ortiz, C. J. Renedo, M. Mañana, F. Ortiz, L. I Eguíluz \\ Department of Electric and Energy Engineering \\ ETSI Industriales y Telecomunicación, University of Cantabria \\ Av Los Castros s/n, 39005 Santander (Spain) \\ Phone: +34 942 201374, fax: +34 942 201385, e-mail: delgadof@unican.es
}

\begin{abstract}
The electric generation produces damages (externalities or environmental costs) that are not contemplated in the costs of this activity. A way to include these damages in the cost is based on the emission rights. In these instruments the total amount of allowed contamination is fixed. It is assigned to the polluting agents by means of emission permissions, creating a market of these, in which the agents can exchange them based on their interests. In 2005, Spain undertook the National Plan of Allocation of Emission Rights 2005-2007 (PNA 2005-2007). This plan has established an emission limit to the electrical sector and it has been translated in the allocation of emission rights. If this emissions limit is surpassed they must acquire rights that cover the exceeded. Thus, the companies must reduce their emissions without increasing their costs. What mix of generation is have to be implement in order to minimize the emissions, avoiding to charge the emission rights in the total generation cost?. If it is impossible to cover the demand without this extra cost, how to diminish it? These questions can be responded using optimization methods.
\end{abstract}

\section{Keywords:}

Optimization, $\mathrm{CO}_{2}$ emissions, emission right, externalities, electricity generation

\section{Introduction}

Most significant impacts of the electrical generation are possibly caused by the atmospheric contamination mainly emissions of $\mathrm{CO}_{2}[1,3]$. All these impacts produce damages (environmental costs or externalities) that are not gathered in the price of the electricity [2]. In other words, the allocation of resources is not optimal from a social point of view, since the prices, understood like tool of the market to assign resources, do not incorporate all the costs and benefits of the different alternatives of generation, transports, distribution and electrical consumption $[4,5]$.

However, still now in considerably liberalized markets like it is the Spanish one, is necessary to take part considering an optimal social benefit, establishing instruments that allow the internalisation of these externalities, incorporating them in the price of the electricity.
Throughout the time two types of instruments have been mainly proposed and applied, with greater or smaller success [6].

The first type of instruments, denominated of mandate and control, have been used by their simplicity of implantation, and therefore, of which more variety and real experiences of application exist: standards of technology, standards of quality of the fuel and the standards of emission

The second type of instruments that are denominated of market, takes advantage of the mechanisms that offers the market, stimulating to the polluting agents to obtain the environmental objective; emphasizing the ecological taxes [9] and the negotiable permissions of emission.

In these last instruments the total amount of allowed contamination is fixed. It is assigned to the polluting agents by means of emission permissions, creating a market of these, in which the agents can exchange them based on their interests. This way, the companies with low costs of contamination reduction will be interested in reducing its emissions, selling the permissions to others with greater costs. The price of purchase of the permission will be established in such a way that it is indifferent to invest in decontaminating or acquiring new permissions.

In 2005, Spain undertook the National Plan of Allocation of Emission Rights 2005-2007 (PNA 2005-2007) and the law 1/2005 of March, by which the regime of Trade of Greenhouse Effect Rights is regulated.

The basic principle of PNA 2005-2007 is the stabilization of the emissions in the average of period 2000-2002. In our case the distribution of Emission Rights for the electrical generation is of $86.4 \mathrm{MtCO}_{2} /$ annuals, considering a forecast of 92.4 emissions of $\mathrm{MtCO}_{2}$ /annuals.

This way, an emission limit has been established for the electrical sector and it has been translated in the 
allocation of emission rights. If this limit of emissions is surpassed they must acquire rights that cover the exceeded. If rights are not acquired the emitting companies will have to pay important fines (40 Euros/tCO $2 \mathrm{e}$ in the period 2005-2007 and 100 Euros/ $/ \mathrm{CO}_{2 \mathrm{e}}$ in the period 2008-2010). It is obvious that the purchase of Emission Rights has been able to internalise an external cost that before was not considered: The impact of the Greenhouse Gas Effect on the climate.

An aspect to consider by the generating companies is the minimization of the emissions. If they would not make it his competitiveness would be reduced and, therefore, its benefits due to the increase of the cost of generation. The generation cost is increased because the cost of emission of $\mathrm{CO}_{2}$ is added.

The questions to respond are: What mix of generation is have to be implement in order to minimize the emissions, avoiding to charge the emission rights in the total generation cost?. If it is impossible to cover the demand without this extra cost, how to diminish it?

These questions can be responded using optimization methods [7]. The optimization consists of the selection of the best alternative by comparing with the other possible alternatives. So, the operation of the system to optimize (to maximize or to minimize) must be measured quantitatively by means of the objective function. This objective function is represented generally by a mathematical expression composed by variables. These variables represent the decisions that can be taken and that affect the value of the objective function. Finally, all system has a set of restrictions that the variables have to satisfy.

The solution of the problem will consist of finding the value that must take these variables to make the objective function optimal without violating the restrictions.

\section{Estimation of the demand and possible maximum annual production of electrical energy in the 2006}

The estimation of the electricity demand growth is fundamental for the calculation that is made later. The forecasts presented in this article gather the hypotheses established by Red Eléctrica de España, S.A. (REE) in their document "Demand Forecasts for every year from the 2004 to 2008" [8], September 2004, next to the revision carried out by that company in November 2004 .

In this article two estimations - scenarios - of the four considered by REE for year 2006, are used. They are the scenarios superior and of maximum growth.

Finally, to make a more exhaustive analysis of the subject the author of this article has added another scenario. It is a superior scenario to the one of maximum growth. It has denominated Max-1.
The justification of this new scenario is based on the demand during 2005, according to the "Advance of the report 2005"[10] of REE, January 2006. The demand has been 259,950 GWh, surpassing in more than 16,000 GWh the scenario of maximum growth fixed in the study of REE for 2005.

Table 1. Scenarios of annual demand in 2006 contemplated in this article.

\begin{tabular}{|c|c|}
\hline $\begin{array}{c}\text { Forecast } \\
2006\end{array}$ & $\begin{array}{c}\text { Power Demand } \\
\text { (GWh) }\end{array}$ \\
\hline Superior & 251,555 \\
\hline Maximum growth & 261,617 \\
\hline Max-1 & 272,000 \\
\hline
\end{tabular}

On the other hand, in table 2, has been considered the possible maximum annual generation for 2006 from the diverse power sources (coal, nuclear...). It is based on the production of these sources in 2005 and some other reasons that we will detail next. According to this report the net generation during 2005 ascended to 267,764 GWh.

The forecast for the hydroelectric generation can be observed as conservative. This is justified in the dry period that has been taken place during the previous years. This has done that the electrical production of 2005 has been the lowest one of the last 48 years. In addition at the end of the 2005 reserves in the dams represented the $41.3 \%$ of their total capacity.

The energy that the nuclear generation can provide is now close to the capacity limit. Its availability indices are superior to $90 \%$ during the last years. Even so, we suppose a slight increase with respect to 2005, based on efficiency improvements and availability.

The generation with coal cannot contribute much more than what it contributes in 2005, due to its high indices of use and elevated production.

During 2005 the number of new combined cycle power stations built, were eight. This supposes an increase of the power available from this generation type in almost 50\%. During 2006 some others power plants will start to work. Considering all the exposed until now, an important increase of the electrical production with natural gas is expected.

The energy supplied by special regime sources has covered around $20 \%$ of the demand during 2005. In addition, $40 \%$ of that energy has come from the wind generation.

Within the energies of the special regime is this last the one that has had the most important increase during 2005 in terms of power available (15\% of increment respect to 2004). The power provided by the rest of energies (cogeneration, biomass...) have not been increased too much during the last year. Based on the previous data one could anticipate that the wind will contribute more to the mix whereas the rest will also undergo an increase. 
Table 2. Production by power source in the year 2005 and forecast for the 2006

\begin{tabular}{|l|c|c|}
\hline \multicolumn{1}{|c|}{ Power source } & $\begin{array}{c}\text { Production 2005 } \\
(\mathrm{GWh})\end{array}$ & $\begin{array}{c}\text { Forecasts of possible maximum production (1) } \\
\text { 2006 (GWh) }\end{array}$ \\
\hline Hydroelectric & & 60,000 \\
\hline Nuclear & 57,539 & 85,000 \\
\hline Coal & 81,313 & 60,000 \\
\hline Natural gas (CCGT) & 49,208 & 20,000 \\
\hline Fuel-oil & 20,192 & 25,000 \\
\hline Wind energy & 20,236 & 35,000 \\
\hline Co-generation and other renewable energies & 30,623 & \\
\hline
\end{tabular}

(1) To point out that the data contributed in the column "Forecasts of possible production Maxima 2006" are approaches

Finally, it is necessary to remark that today the generation with fuel is an old technology. In fact it is the only technology which has lost generation power during 2005 (6.6\%). However, it has contributed to the system with about 20,000 GWh. By all the previous considerations, we assume that in 2006 it can continue contributing with the same amount of energy.

\section{Formulation of the problem}

We are going to make the model of the Spanish generating system with the purpose of finding the mix of suitable generation that diminishes the cost of generation of electrical energy. In the optimization, the annual generation of each source will be determined in order to diminish the production costs, where the environmental costs are included. For it, a number of simplifications have been made. Some of them have been exposed in the previous section.

The annual electrical demand is covered by the mentioned power sources in the previous section. This demand includes: scenarios presented by REE in its report of the previous section as well as consumptions of the generation and the consumption in pumping stations. These two last consumptions have been determined by means of percentage. In order to determine the consumptions of the generation it has been applied 4.5\% to the net generation of the ordinary sources. The consumption of the pumping stations has been determined applying $2.5 \%$ to the net generation (ordinary generation +special regime generation -consumptions of the ordinary generation).

Finally, to the three consumptions previously mentioned forecast of demand REE, consumptions of the ordinary generation, consumptions of pumping stations - it is had to add a fourth consumption: the international balance. The exchange of energy with other countries is negligible due to Spain is practically a "power island". For that reason, the international balance has been considered null.

The planning is going to be made based on the production, not on the installed power. For it, it is considered initially, a maximum generation by power source.
In order to establish the production cost; only the generation costs of the power sources in the ordinary regime have been considered. For that reason, the energy provided by the power sources of the special regime is removed from the total annual demand. The power sources of the ordinary regime will cover the rest.

The production costs of the diverse technologies of electricity generation have been extracted of the Green Book of the European Union of 2000 [11]. The $\mathrm{CO}_{2}$ emissions have been extracted of existing bibliography. In table 3 , the costs of generation and the $\mathrm{CO}_{2}$ emissions for the considered options are shown.

Table 3. Costs of generation and emissions by technology

\begin{tabular}{|l|c|c|}
\hline Power source & $\begin{array}{c}\text { Cost } \\
(\text { euros/kWh) }\end{array}$ & $\begin{array}{c}\text { Emissions de } \mathrm{CO}_{2} \\
(\mathrm{~kg} / \mathrm{kWh})\end{array}$ \\
\hline Coal & 0.040 & 0.997 \\
\hline Nuclear & 0.047 & 0 \\
\hline Natural gas & 0.035 & 0.365 \\
\hline Fuel-oil & 0.051 & 0.983 \\
\hline Hydroelectric & 0.040 & 0 \\
\hline
\end{tabular}

Considering all the previous assumptions the exposition of the problem is:

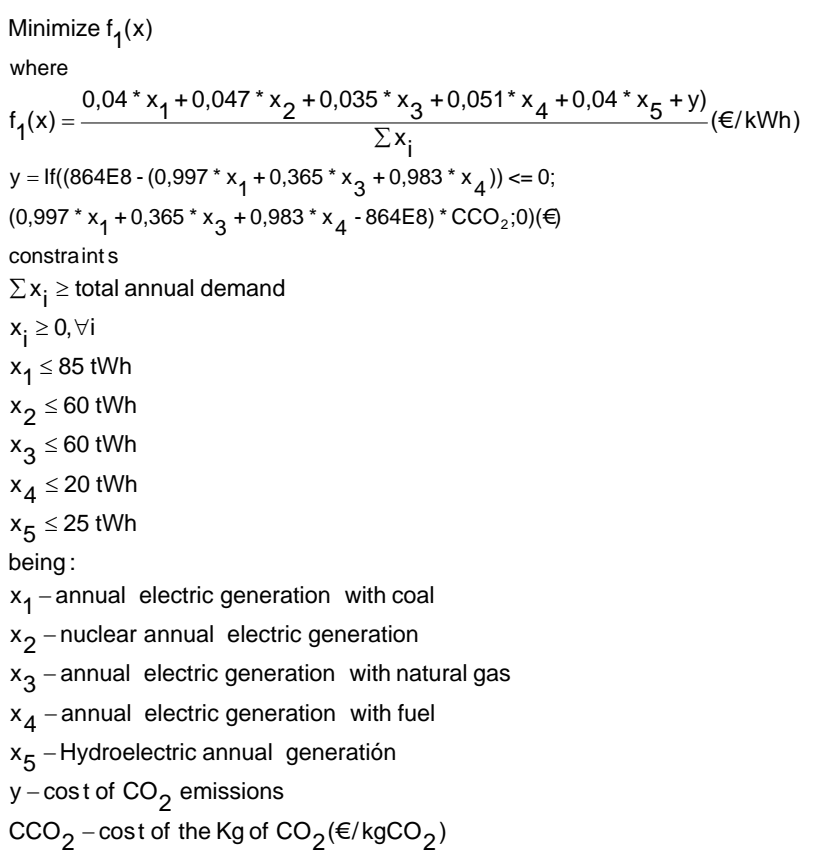


As it is observed in the objective function, $f_{1}(x)$, a variable; $y$, represents the annual cost of the $\mathrm{CO}_{2}$ emissions. If those emissions do not surpass 86.4 $\mathrm{MTCO}_{2 \mathrm{e}}$ /year the cost will be null. If they surpass it, this will entail an added cost. The value of this added cost will depend as much on the amount of emission as on the price of the $\mathrm{kg}$ of $\mathrm{CO}_{2}$. For that reason, in addition to the three contemplated scenarios of demand, four possible prices of the $\mathrm{CO}_{2}$ ton, $11 € / \mathrm{tCO}_{2 \mathrm{e}}{ }^{1}, 15 € / \mathrm{tCO}_{2 \mathrm{e}}, 20$ $€ / \mathrm{tCO}_{2 \mathrm{e}}, 25 € / \mathrm{tCO}_{2 \mathrm{e}}{ }^{2}$. have been considered.

Finally, it is indicated that the optimization has been made by means of the tool solver from the spreadsheet Excel.

\section{Empirical results}

Next, it appears a series of graphs with the results obtained for the different demand scenario with different prices of the $\mathrm{CO}_{2}$ ton.

\subsection{Costs of the kWh}

Figure 1 presents the increase that supposes the introduction of the environmental costs in the production costs.

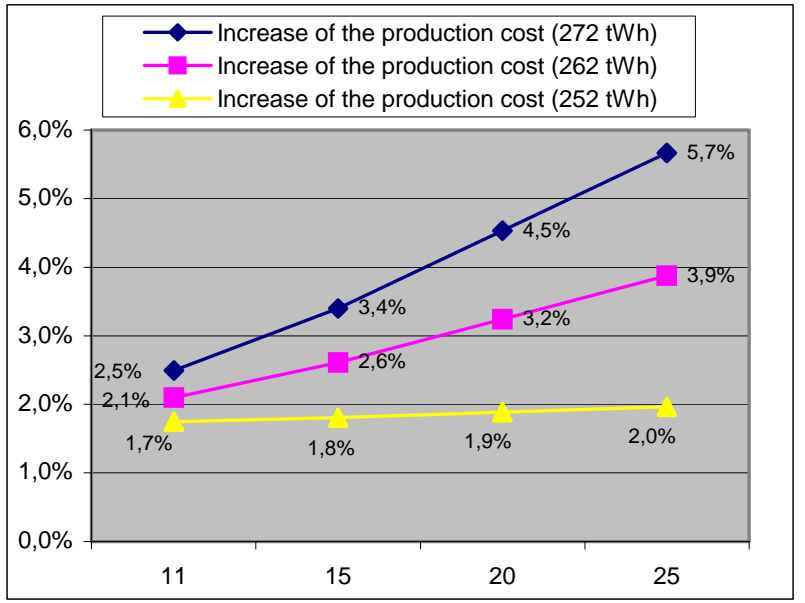

Figure 1 Increase of production cost with PNA

The production costs without including the PNA are, respectively: $3.99 \mathrm{c} € / \mathrm{kWh}$ for the smaller scenario, 4.02 $\mathrm{c} € / \mathrm{kWh}$ for intermediate scenario and $4.06 \mathrm{c} € / \mathrm{kWh}$ for the greater scenario. It is observed in these values that the no inclusion of the environmental costs causes that when the coal and the fuel start to generate the production cost is increased very slightly.

Once the environmental costs are included, the price of $\mathrm{kWh}$ is increased. Being more concrete, in the Max-1 scenario the production cost would be increased between

\footnotetext{
1 “An analysis of the consequences of the Carbon Trading Directive and the permit assignment methods on the Spanish electricity sector”,IIT;UPC 2004.

2 “Climate change for Europe's utilities”. The Mckinsey Quarterly Number 1, 2003
}

$2.5 \%$ for $11 € / \mathrm{tCO}_{2}$ and $5.7 \%$ for $25 € / \mathrm{tCO}_{2}$ respect to 4.06 $€ /$ kWh.

\subsection{Generation by power source}

The figures 2, 3 and 4 present the production of each power source in the ordinary regime and for each of the three scenarios considered.

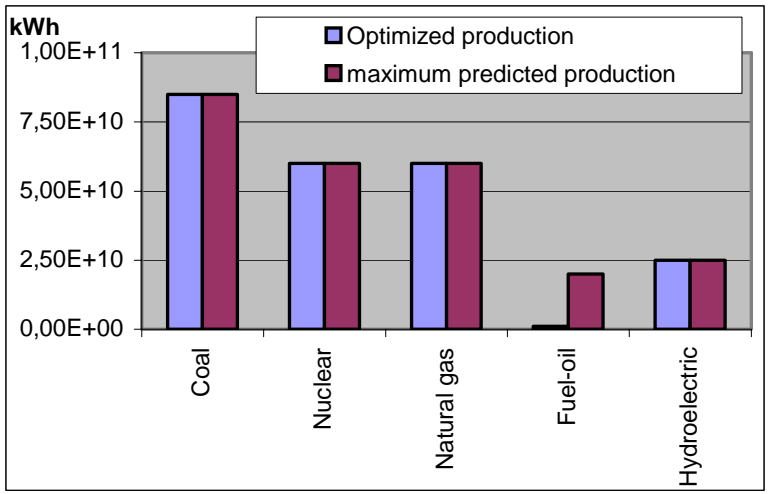

Figure 2. Generation by power source. Scene: 272 TWh

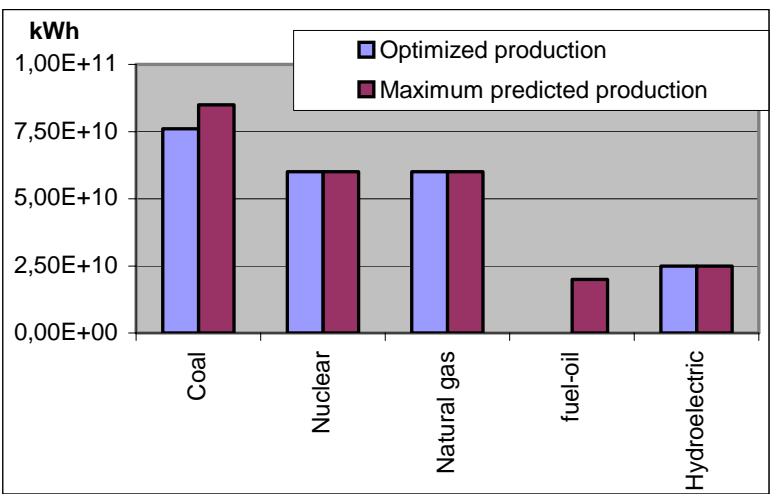

Figure 3. Generation by power source. Scene: 262 TWh

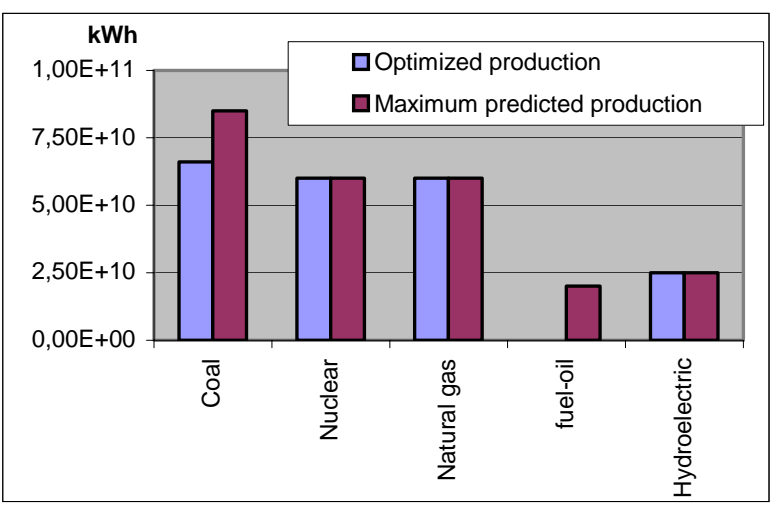

Figure4. Generation by power source. Scene: 252 TWh

The "clean sources" - nuclear, natural gas and hydroelectric- provide the possible maximum annual production because they do not emit $\mathrm{CO}_{2}$. The environmental impacts of these power sources should be considered in order to make a more trustworthy study.

In the scenario of maximum demand, the participation of the fuel oil, to cover the demand, is needed. It entails that 
the production cost is strongly increased by its high $\mathrm{CO}_{2}$ contribution.

Finally, we see that in both scenarios of smaller demand the fuel oil does not participate and the coal reduces its contribution.

\subsection{Emissions}

Figure 5 presents the $\mathrm{CO}_{2}$ emissions for the three scenarios contemplated.

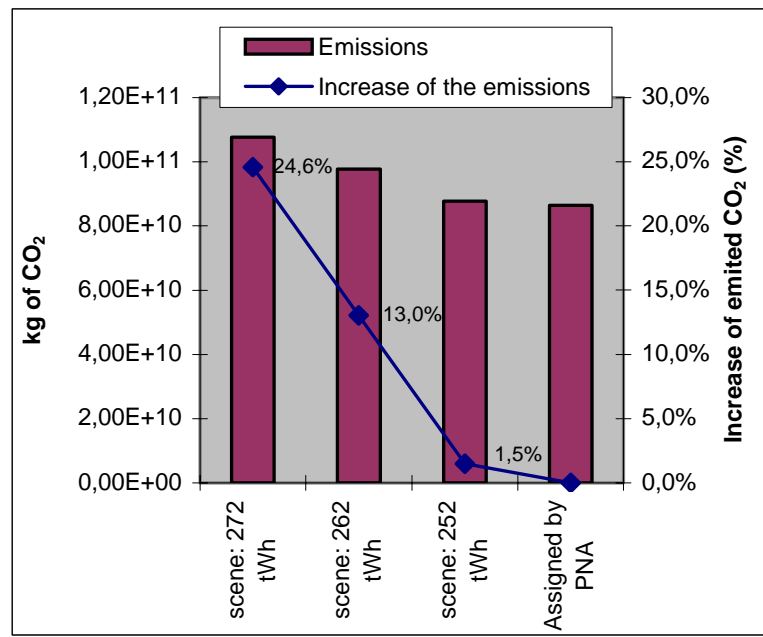

Figure 5. $\mathrm{CO}_{2}$ emissions in scenarios and increases respect of PNA

An important increase of the $\mathrm{CO}_{2}$ emissions is observed in the scenarios of greater demand $-24.6 \%$ and $13 \%$-.

Apart from the increase that supposes in the production cost, it entails the risk of not being able to meet the Protocol of Kioto: the reduction of the $\mathrm{CO}_{2}$ emissions.

\subsection{Optimized production without PNA}

The figures 6 and 7 present the distribution of the production in the absence of the environmental costs for two of the scenarios. The scenario of maximum demand corresponds with the figure 4 .

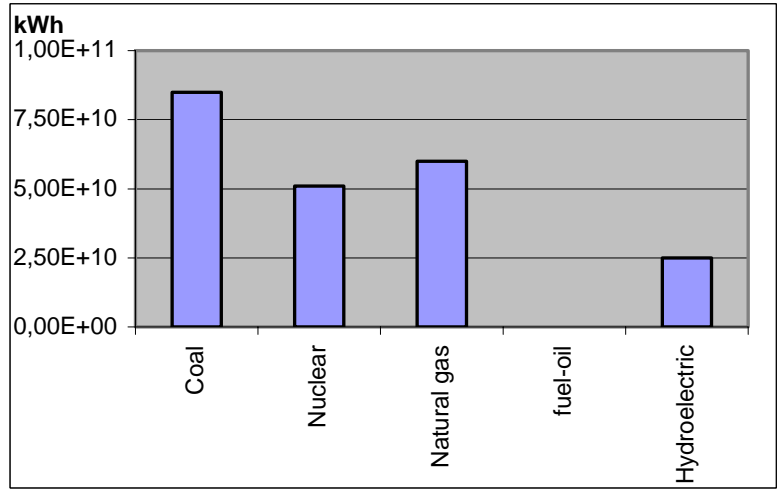

Figure 6. Optimized production without PNA. Scene 262 TWh

As it is possible to observe, if the technical conditions would not avoid it, in the absence of the PNA and considering solely economical criteria it would be the nuclear energy the one that has to be reduced after the fuel.

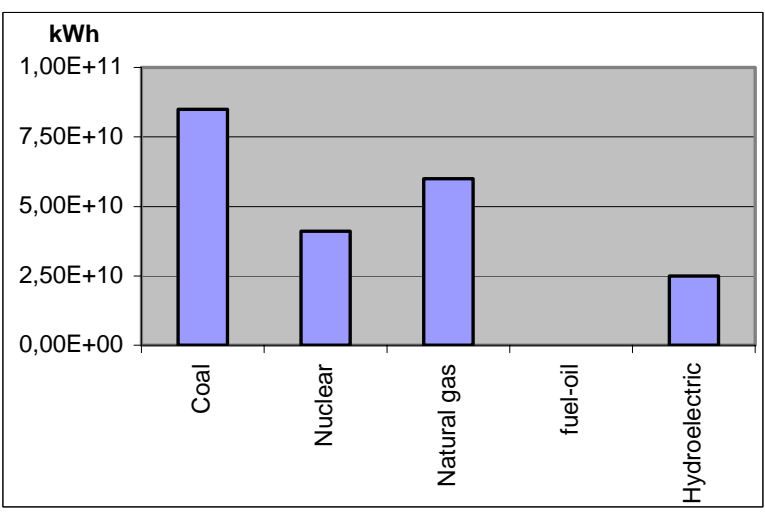

Figure 7. Optimized production without PNA. Scene 252 TWh

\section{Conclusions}

It has reached the following conclusions after the analysis of the graphs:

- It is observed in the production costs, without including the PNA, that the no-inclusion of the environmental costs entail that the price of the production is affected very slightly when pollutant power sources start to generate. (1.75\% between the smaller scenario and the greater one).

- When the environmental costs are included the greater increases of the production cost take place for the Max-1 scenario: between 2.5\% and the $5.7 \%$. This is because in this scenario the participation of the fuel oil power stations is necessary to cover the demand. In the other two its participation is not necessary. This fuel, although it contributes with little energy to the mix, is from the economic point of view very onerous: it is an expensive fuel and in addition it contaminates a lot. For that reason, it is first in leaving the generation.

- In the three scenarios it is observed that the "clean sources" - nuclear, natural gas and hydroelectricparticipates with the maximum possible production.

- In the scenario of maxima demand the participation of the fuel oil is needed to cover the demand. It entails that the production cost is strongly increased by its high $\mathrm{CO}_{2}$ contribution.

- It is observed that in both scenarios of smaller demand the fuel oil does not generate and the coal diminishes its contribution. The coal starts to generate before the fuel oil. It affects very positively the production cost because both power sources are very pollutant.

- $\quad$ The three scenarios are over the emission allowed by the PNA. This implies that the acquisition of emission rights will be necessary. The companies with highly polluting power sources will have to undergo an added cost to the total production cost. 
- $\quad$ It has been surpassed widely the limits of emission established by the PNA (108, 98 and 88 MTCO2/year) in the three scenarios. Apart of the extra cost a risk is originated: Not to meet the European agreements derived from the Protocol of Kioto. In these agreements the emission limits for Spain is a $15 \%$ more than what was emitted in 1990.

- It seems clear that the introduction of the environmental costs of $\mathrm{CO}_{2}$ emission supposes a change in the generation options. If one did not consider these costs the nuclear power source should be disconnected after the fuel oil, taking into account the production cost.

\section{References}

[1] Devezeaux J.G. Enviromental Impacts of Electricity Generation. The Uranium Institute $25^{\text {Th }}$ Annual Symposium. 30 August-1 september 2000. London

[2] Starfelt N. External costs of Electricity Generation in Sweden. Uranium Institute Annual Symposium. 1994
[3] Hirschberg S., Heck T. Health an enviromental impacts of China's current and future electricity supply, with associated external costs. Int. J. Global Energy Issues, Vol.22, Nos 2/3/4/2004

[4] El-Kordy M.N., Bard M.A. Economical evaluation of electricity generation considering externalities. Renewable Energy 25 (2002) 317-328

[5] Kuri B.Valuing Emissions from Electricity Generation: Towards a low Carbon Economy. IEEE

[6] Kypreos S., Krakowski R. Introducing externalities in the power generation sector of China. Int. J. Global Energy Issues, Vol. 22, Nos 2/3/4, 2004

[7] Schwarz H.G. Modernisation of existing and new construction of power plants in Germany: results of an optimisation model. Energy Economics 27(2005)

[8] "Forecasts of cover of the demand for every year from the 2004 to 2008", Red Eléctrica de España, S.A. (REE). September, 2004

[9] Voorspools K., Peersman I. A comparative analysis of energy and $\mathrm{CO}_{2}$ taxes, on the primary energy mix, for electricity generation. Int. J. Energy Res. 2005; 29:879[10] "Advance of report 2005". REE, January, 2006

[11] Green book of European Union. 2000 